\title{
Novel delivery methods bypassing the blood-brain and blood-tumor barriers
}

\author{
Benjamin K. Hendricks, BS, ${ }^{1}$ Aaron A. Cohen-Gadol, MD, MSc, ${ }^{1,2}$ and James C. Miller, MD ${ }^{1}$ \\ ${ }^{1}$ Goodman Campbell Brain and Spine, Indiana University Department of Neurological Surgery; and ${ }^{2}$ Indiana University Health \\ Melvin and Bren Simon Cancer Center, Indianapolis, Indiana
}

\begin{abstract}
Glioblastoma (GBM) is the most common primary brain tumor and carries a grave prognosis. Despite years of research investigating potentially new therapies for GBM, the median survival rate of individuals with this disease has remained fairly stagnant. Delivery of drugs to the tumor site is hampered by various barriers posed by the GBM pathological process and by the complex physiology of the blood-brain and blood-cerebrospinal fluid barriers. These anatomical and physiological barriers serve as a natural protection for the brain and preserve brain homeostasis, but they also have significantly limited the reach of intraparenchymal treatments in patients with GBM.

In this article, the authors review the functional capabilities of the physical and physiological barriers that impede chemotherapy for GBM, with a specific focus on the pathological alterations of the blood-brain barrier (BBB) in this disease. They also provide an overview of current and future methods for circumventing these barriers in therapeutic interventions. Although ongoing research has yielded some potential options for future GBM therapies, delivery of chemotherapy medications across the BBB remains elusive and has limited the efficacy of these medications.
\end{abstract}

http://thejns.org/doi/abs/10.3171/2015.1.FOCUS14767

KEY WORDS glioblastoma; blood-brain barrier; blood-tumor barrier; Gliadel; mannitol; ultrasound; thermotherapy; nanoparticle; liposome; stem cell

$\mathrm{G}$ LIOBLASTOMA (GBM) is the histological type of World Health Organization Grade IV astrocytic malignant tumors of the brain. According to the Central Brain Tumor Registry of the United States, with $45.6 \%$ of all malignant brain tumors, GBM was the most common malignant brain tumor from 2006 to 2010, and it represents $15.4 \%$ of all primary tumors. ${ }^{125}$ The median age of patients at GBM diagnosis is 64 years, and the male/ female predominance ratio is $1.6 .{ }^{125}$ Although brain tumors are relatively rare compared with the most prevalent types of cancer, GBM disproportionally carries high rates of morbidity and mortality. The current standard of care includes cytoreductive surgery or biopsy combined with adjuvant chemoradiation using temozolomide (TMZ). ${ }^{13}$ With these standard interventions, the 5-year survival rate of patients with GBM is $<5 \%$, the mean survival is approximately 14 months, and the disease nearly universally recurs. ${ }^{25,125,140}$ Survival rates worsen with increasing age, such that in patients $>65$ years the mortality rate at 5 years is greater than $98 \% .{ }^{125}$ This grim prognosis is due in part to barriers to efficacious delivery of pharmaceutical therapy, and these barriers are discussed in this review.

The relatively limited access of chemotherapy medications to the microenvironment of a malignant brain tumor is a major obstacle to their delivery. This limited access is due to 2 major structural barriers: the blood-brain barrier (BBB) and the blood-cerebrospinal fluid barrier (BCSFB). Both barriers provide biomechanical and cellular resistance to pharmaceutical extravasation and to the exposure of the parenchymal tissues of the central nervous system (CNS) to chemotherapy agents. Experimental manipulation to circumvent these obstacles has been a major focus of research into the treatment of GBM and other malignant diseases of the CNS.

ABBREVIATIONS BBB = blood-brain barrier; BCSFB = blood-cerebrospinal fluid barrier; $\mathrm{BTB}=$ blood-tumor barrier; $\mathrm{BV}=$ bevacizumab; $\mathrm{CNS}=$ central nervous system; CSC = cancer stem-like cell; CSF = cerebrospinal fluid; GBM = glioblastoma; $\mathrm{LTH}=$ liposomal Trojan horse; $T M Z$ = temozolomide; VEGF = vascular endothelial growth factor.

SUBMITTED November 3, 2014. ACCEPTED January 5, 2015.

INCLUDE WHEN CITING DOI: 10.3171/2015.1.FOCUS14767.

DISCLOSURE The authors report no conflict of interest concerning the materials or methods used in this study or the findings specified in this paper. 


\section{The BBB: Anatomy and Physiology}

\section{Anatomical Features}

The BBB constitutes the interface between the brain parenchyma and its vascular supply vessels. It is one of several systems that defend against the intrusion of foreign substances into the CNS, and it also maintains CNS homeostasis, including ionic and fluid balances. Thus, the BBB shields CNS neurons from systemically circulating hormones, inflammatory mediators, waste products, strongly fluctuating ionic concentrations, and toxic compounds. ${ }^{67,147}$ It also prevents the egression of CNS neuropeptides and neurotransmitters into the general circulation. ${ }^{67}$ Therefore, the $\mathrm{BBB}$ serves to isolate both CNS and systemic fluid contents via a multifaceted regulatory process.

Structurally, the BBB comprises capillary endothelial cells with adjoining tight junctions overlying a continuous, nonfenestrated basal lamina (Fig. 1A). ${ }^{148}$ The tight junctions restrict paracellular substrate flux and separate the apical and basal cellular domains with associated peripheral membranous protein complexes to establish specific functional domains. ${ }^{3}$ Invested pericytes are bounded by the basal lamina of the endothelium, and a second layer of basal lamina adjacent to the astrocytic interdigitating endfoot processes of the perivascular space forms a sheathed neurovascular structure. ${ }^{1,3}$ This structural barrier to solute movement is the rigid frame on which physiological modification will mediate transport of solutes across the BBB.

Detailed evaluation of the BBB has shown poor permeability for solutes $>500$ D. ${ }^{103}$ Molecules such as ethanol
(46.1 D), nicotine (162.2 D), and caffeine (194.2 D) are passively transported across the luminal and abluminal membranes, and the efficiency of this transport is determined by the lipophilic characteristics and molecular sizes of these compounds. ${ }^{174}$ Other less lipophilic and larger molecules such as glucose (180.2 D), insulin (6 kD), and albumin $(6.6 \mathrm{kD})$ use solute carriers (GLUT-1), receptormediated transport, and absorption-mediated transport, respectively. ${ }^{174}$ Orally dosed TMZ (194 D) has approximately $20 \%$ relative penetration across the normal BBB because of the small molecular size, lipophilic properties, and efflux pump specificity of TMZ.,124 In summary, the BBB permeability to macromolecules is determined by a multifactorial anatomical and physiological milieu.

\section{Physiological Features}

The physiological contribution of astrocytes to the BBB involves modulating the cytoarchitecture of the endothelial tight junctions, determining the polarization of transport systems, and enhancing the expression of enzymatic mechanisms. ${ }^{174}$ Because astrocytes maintain the anatomical and physiological function of the BBB, diseases affecting astrocytes can, in turn, dramatically affect the BBB. For example, water transport across the BBB is primarily mediated by aquaporin 4, which is expressed along astrocytic endfeet of the neurovascular unit and controls the flows of ions, macromolecules, and fluids. ${ }^{121,166}$

The endothelial lining of the neurovascular unit also possesses a multitude of transport proteins, including ABCB1 (P-glycoprotein), ABCC (MRP) transporters, ABCG2

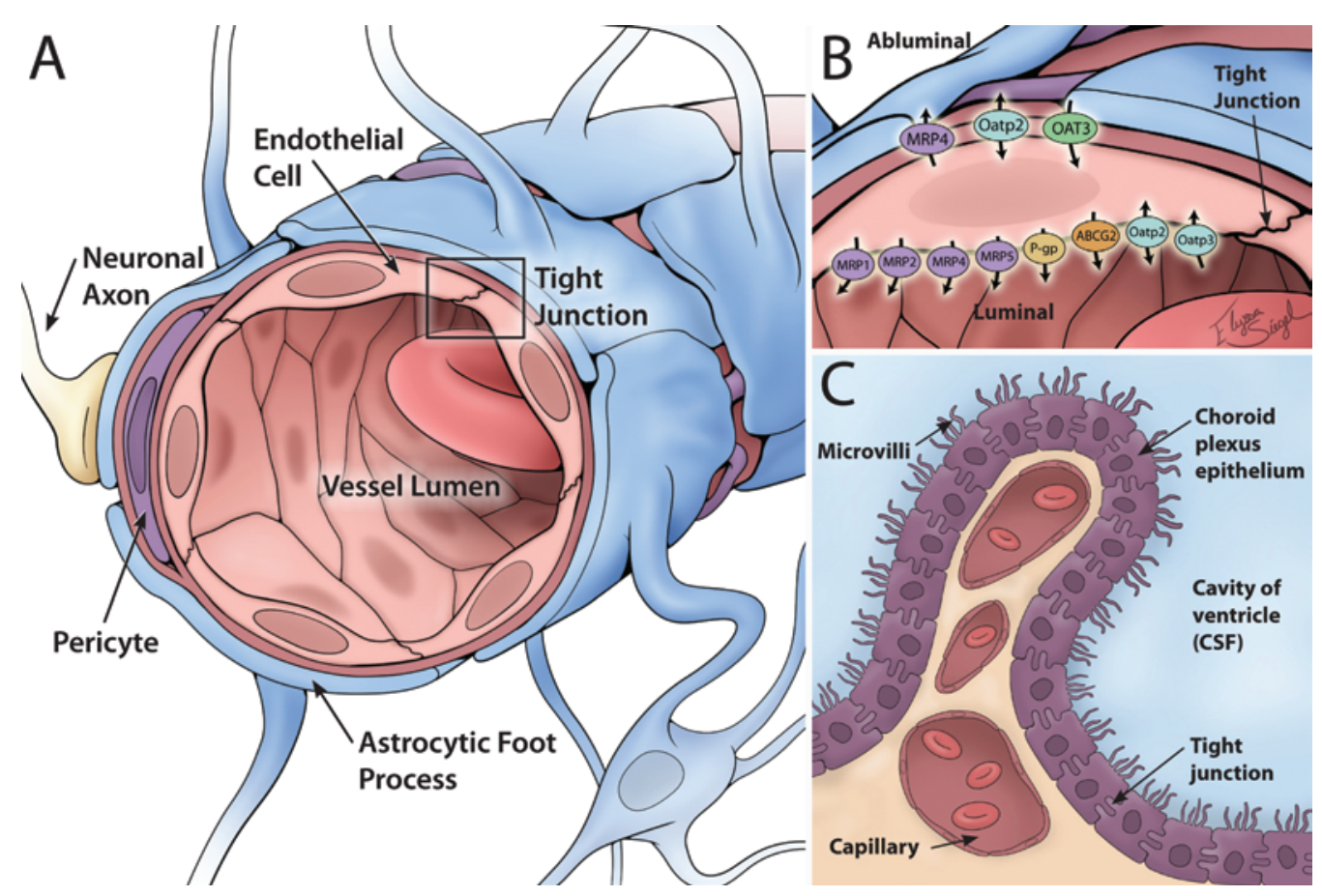

FIG. 1. Barriers to CNS access. A: The neurovascular unit is composed of the endothelial lining, the basal lamina, ensheathed pericytes, and astrocytic endfeet. B: Solute transporters on the endothelial surface are major barriers to extravasation of chemotherapy agents. C: The blood-CSF barrier serves as the interface between the vasculature and the CSF and is composed of the choroid plexus epithelium. Copyright Aaron Cohen-Gadol. Published with permission. 
(BCRP), OAT3 (SLC22a8), OATP2, and OATP3148 (Fig. 1B). These transporters have major physiological significance for resistance to chemotherapeutic agents in GBM therapy. They mediate efflux of xenobiotics from the endothelium or into the endothelium away from the intraparenchymal fluid compartment, effectively clearing these agents into the luminal compartment.

In addition to the transport barrier at the $\mathrm{BBB}$, intracellular and extracellular catabolic enzyme processes also contribute to the barrier within both the endothelium and astrocytes. ${ }^{2}$ One enzymatic process of particular importance is the O-6-methylguanine-DNA methyltransferase reaction, whose increased activity generates TMZ resistance. ${ }^{87}$ Therefore, for an agent to traverse the BBB, the agent must circumvent the anatomical barrier, avoid efflux transport, and evade enzymatic conversion to an inactive metabolite.

Representing another interface with the brain parenchyma, the cerebrospinal fluid (CSF) compartment may serve as an additional avenue for drug delivery. The composition of the CSF is highly regulated through a modifiable barrier at the choroid plexus epithelium, referred to as the blood-CSF barrier (BCSFB) (Fig. 1C). The BCSFB is composed of choroid plexus epithelial cells, a basal membrane, apical microvilli, and a fenestrated endothelial lining of the choroidal vasculature. ${ }^{148}$ To facilitate secretory control, the choroid plexus epithelium is adjoined by tight junctions that are absent from the adjacent ependymal and pial epithelial linings. ${ }^{158}$ To produce and secrete CSF, the choroid plexus has an array of papillary structures within the brain's ventricular system. As shown in rat models, the choroid plexus receives the highest local blood flow in the brain, despite a surface area $\left(75 \mathrm{~cm}^{2}\right)$ similar to that of the BBB ${ }^{148}$ Given that its permeability is greater than that of the $\mathrm{BBB}$, with a flux rate inversely proportional to the molecular weight of the solute ${ }^{128,132}$ and a permeability generally limited to molecules smaller than $400 \mathrm{D}$, the physical properties of the choroid plexus offer a potential delivery route for chemotherapy through the BCSFB. ${ }^{60}$

However, for each millimeter of depth within the leptomeningeal space, the distribution of a solute via diffusion decreases logarithmically. For small lipophilic molecules, a distance of 500 microns results in a 10-fold drop in diffusion, and diffusion of larger molecules is even less efficient in this space. ${ }^{128}$ The leptomeningeal space provides 2 anatomical locations for the exchange between the CSF and brain parenchyma. One exchange conduit is through the ependymal cell surface within the ventricles, and the other via the subarachnoid space because there is no substantial permeability barrier along the pial surface. ${ }^{148,172}$ Neither of these surfaces has tight junctions for control of paracellular permeability. Although the pial surface is not a formidable barrier to the passage of molecules, a network of glial cells forms the glia limitans, which regulates the diffusion of macromolecules. ${ }^{68}$ The CSF-to-parenchyma penetration by macromolecules occurs at rates faster than can be explained by passive diffusion alone; therefore, it has been hypothesized that translocation across the CSF-parenchymal interface involves active transport mechanisms. ${ }^{127}$ By modifying these specific secretory and permeability mechanisms involved in the production of
CSF, a tumor may alter the brain's biochemical microenvironment. ${ }^{88,171}$

In summary, the BBB/BCSFB represents a controlled entry system for the CNS, accessible along the neurovascular unit via 2 cellular transport processes: simple diffusion of lipophilic compounds across the endothelium and transporter-mediated delivery of macromolecules and ions; $;^{15,148,174}$ both are possible conduits for strategic drug delivery ${ }^{147}$ However, the systems described above are not the settings through which most drug delivery is preferred, because the environment of a malignant tumor undergoes significant changes, which will be discussed in the next sections.

\section{Effects of Malignant Neoplasia on the BBB}

A malignant tumor results in many changes that contribute to specific pathological disruptions of the BBB. These disruptions include an alteration within the tumor mass referred to as the blood-tumor barrier (BTB) and diffuse, remote changes within the neurovascular system. ${ }^{73}$ Those discussed in this review include alterations in vascular permeability, hypoxia-induced changes, and modifications in solute-carrier proteins.

Pathological vascular changes within the GBM can be attributed to the astrocytic diffuse upregulation and redistribution of aquaporin $4,3,121$ decreased claudin and occludin expression within the tight junction complex, ${ }^{102}$ basement membrane disruption,,$^{51}$ and leaky neovascularization. ${ }^{150}$ These changes all enhance the permeability across the BTB, facilitating influx of proteins and inflammatory mediators into the brain parenchyma. The BTB displays a heterogeneous breakdown in control of permeability, ${ }^{150}$ which, in theory, is localized primarily to the tumor core. The adjacent BBB, as well as the tumor periphery, appears to retain permeability-resistance properties. ${ }^{45,168,169}$ A focal edematous state in the surrounding parenchyma, enhancing hydrostatic interstitial pressure, would theoretically compensate for the enhanced BTB permeability and potentially decrease the time-concentration exposure of chemotherapy agents delivered across the BTB.${ }^{118}$ Overall, the enhanced BTB permeability does not ensure optimal pharmacokinetics of these agents because of a multifactorial dependence on efflux transporters and altered dynamics of cerebral fluid flow that accompany the BTB state.

The BTB neovascularization is of particular relevance to therapy because this neovascularization significantly determines the permeability of the local tumor neurovascular unit. This microvasculature can be classified as 1 of 3 endothelial types: continuous nonfenestrated endothelium, continuous fenestrated endothelium, or discontinuous endothelium. ${ }^{143}$ The first exhibits permeability similar to that of the normal neurovascular unit, and the latter 2 types exhibit permeability dependent on pore area and the molecular weight of the fluxing macromolecule. ${ }^{143}$ In addition, microvessel diameter and density are compounding variables that result in a highly heterogeneous angioarchitecture of the GBM. ${ }^{52}$ This heterogeneity may be explained by the fact that the pericyte precursors for neovascularization are derived from glioma stem cells. ${ }^{40}$ Theoretically, profiling the vascular cell population of a 
tumor before chemotherapy could predict the efficacy of the intervention and suggest certain BTB circumvention mechanisms to increase chemotherapy delivery.

Interrelated with vascular changes associated with GBM, hypoxia and acidotic microenvironmental conditions all contribute to BTB permeability through induction of hypoxia inducible factor 1 (HIF1). ${ }^{122}$ Induced production of vascular endothelial growth factor (VEGF) contributes directly and indirectly to hypoxia via neoangiogenic tortuous and leaky vasculature that enhances BTB permeability caused by gaps in the basement membrane and endothelium, ${ }^{86,150}$ as described above. The HIF $\alpha 1$ receptor and VEGF expression are precipitous within GBM stem and non-stem cells. ${ }^{39,51}$ This modifiable physiological response to hypoxia is the target for GBM therapy via antiangiogenic pharmaceuticals such as bevacizumab (BV).30,37

Through tumor-induced alteration in the expression of transporter proteins, solute-carrier proteins operate in the BTB of a GBM, being expressed in neoplastic cells and along the neurovascular endothelium..$^{51,107}$ These proteins impede GBM therapy because they reflux chemotherapy agents that have reached the parenchyma or endothelial cells back into the vasculature. ${ }^{148}$ The pathophysiology of GBM often involves the upregulated expression of these efflux systems resulting in chemotherapeutic resistance; chemotherapy agents to which this reflux phenomenon applies include paclitaxel, docetaxel, imatinib, topotecan, and TMZ. ${ }^{24,69,100,116}$ The $\mathrm{x}_{\mathrm{c}}{ }^{-}$antiporter promotes elution of glutamate from tumors, and this excess glutamate is hypothesized to contribute to the excitotoxic death of the surrounding healthy parenchyma and to promote GBM extension into a zone free of contact inhibition. ${ }^{50,51}$ These solute-transport pumps provide pharmaceutical targets that could be tailored to individual tumors according to the dominant tumor transcriptome, to minimize resistance and promote chemotherapeutic efficacy, as has been shown in murine models. ${ }^{116}$

\section{Surgical Implications of the BBB and BTB}

The pathologic condition of the BTB, as described above, exhibits enhanced permeability due to leaky neovasculature and disruption of structural barriers. ${ }^{150}$ This altered state facilitates the use of the photosensitive agent fluorescein to guide resection of gliomas through a preferential tropism of this agent for penetrating pathological BBB locations, ${ }^{142}$ such as the BTB. Although lacking a control comparison group, a recent study demonstrated an $80 \%$ complete resection rate of contrast-enhancing tumors when the resection was assisted by fluorescein guidance. ${ }^{5}$ Fluorescein guidance relies on BBB permeability and not on uptake by glioma cells, as is the case with the tumor marker 5-aminolevulinic acid; ${ }^{5}$ therefore, the presence of cells resistant to permeability within the tumor periphery could decrease the sensitivity of fluorescein's marking capability in regions with a peripherally infiltrating cell population. ${ }^{45,168,169} \mathrm{By}$, in theory, containing the greatest BBB disruption, the tumor core would be less likely to contribute to errors in fluorescein marking. Despite the possibility of not adequately delineating the tumor periphery, fluorescein showed $94 \%$ marking sensitivity when compared with biopsy data. ${ }^{5}$ However, the knowledge that the tumor periphery is likely to maintain barrier permeability could justify a more conservative wider margin of resection.

\section{Methods for Circumventing the BBB}

The $\mathrm{BBB} / \mathrm{BTB}$ provides a unique challenge for researchers to target malignant disease in the CNS because these barriers prohibit entry of chemotherapy agents into this region. Various strategies have been explored to circumvent the BBB with the goal of effective chemotherapeutic penetration. These methods include prodrug formulations, chemical barrier disruption, biochemical drug modification, intraarterial injection, surgical circumvention, hyperosmotic barrier disruption, lipophilic carrier molecules, nanoparticle-delivery vehicles, convectionenhancement delivery, disruption of efflux transporters, thermotherapy, viral vehicles, and stem cell-mediated delivery (Table 1). Several of these circumvention methods that have shown promise or are historically important are discussed in the following. We caution against implying therapeutic efficacy of the abovementioned methods when they have been tested in vitro or when nonprimary tumors were used as a model system for human GBM.

\section{Prodrug-Mediated Therapy}

Prodrug-formulated agents are a theoretical approach to BBB penetration that would involve administering an agent that becomes chemotherapeutically active through enzymatic modification after it has crossed the BBB. This enzymatic modification would render the chemotherapy agent less permeable and thus less prone to removal from the parenchyma. This increased residence time would increase the time-concentration product, while leaving the total body exposure unchanged. ${ }^{73}$ To our knowledge, this approach has not been investigated thus far for GBM therapy in vitro or in vivo. Therefore, it remains a theoretical method for delivery of chemotherapy agents.

\section{Chemical-Mediated Disruption}

Chemical disruption involves exposing the BBB to an agent that transiently increases BBB permeability. Research into this approach has yielded results with intraarterially infused vasoactive compounds such as leukotriene C4, ${ }^{17}$ alkylglycerols, ${ }^{58}$ interleukin- $2,{ }^{75}$ RMP- $7,{ }^{63}$ bradykinin, ${ }^{46,83}$ and tumor necrosis factor- $\alpha /$ interferon- $\gamma .^{104}$ These agents induce a transient inflammatory reaction within the endothelium, resulting in enhanced paracellular permeability and increased chemotherapeutic concentration in the parenchyma. Black and $\mathrm{Chio}^{17}$ encountered initial obstacles to this approach in 1992, such that leukotriene C-4 opened the BBB only enough to facilitate passage of small hydrophilic molecules and not of larger dextrans. Subsequent in vivo attempts have used the bradykinin and kinin analog RMP-7, which has been shown to generate greater disruption than leukotriene C-4; however, RMP-7 produces side effects, including headache, nausea, vomiting, hypertension, and tachycardia.$^{63}$ Moreover, only a very modest increase in BBB enhancement was observed in in vivo models of cisplatin with leukotriene C- $4^{18}$ and of carboplatin with RMP-7.63,71,109 
TABLE 1. Methods for circumventing the blood-brain barrier in GBM treatments

\begin{tabular}{|c|c|c|}
\hline Delivery Method & Description & Most Recent Clinical Trial \\
\hline $\begin{array}{l}\text { Chemical-mediated BBB dis- } \\
\text { ruption }\end{array}$ & $\begin{array}{l}\text { Transient inflammatory response in endothelial lining, } \\
\text { investigated w/ LTC4, alkylglycerols, IL-2, RMP-7, } \\
\text { bradykinin, \& TNF- } \alpha / \text { /FN- } \gamma\end{array}$ & $\begin{array}{l}\text { Warren et al., } 2001 \text { \& 2006; Grant et } \\
\quad \text { al., } 2002\end{array}$ \\
\hline Hyperosmotic BBB disruption & $\begin{array}{l}\text { Endothelial dehydration, cell body shriveling, \& tight } \\
\text { junction disruption; mannitol primarily investigated }\end{array}$ & $\begin{array}{l}\text { Boockvar et al., 2011; Guillaume et al., } \\
2010\end{array}$ \\
\hline IA delivery & IA injection, often combined w/ hyperosmotic disruption & Burkhardt et al., $2012^{28}$ \\
\hline Convection-enhanced delivery & $\begin{array}{l}\text { Intratumoral infusions from surgically placed micro- } \\
\text { pumps }\end{array}$ & $\begin{array}{l}\text { White et al., 2012; Bogdahn et al., } \\
\text { 2011; Kunwar et al., 2010; Carpen- } \\
\text { tier et al., } 2010\end{array}$ \\
\hline $\begin{array}{l}\text { Intraventricular \& intrathecal } \\
\text { injection }\end{array}$ & $\begin{array}{l}\text { Agent injection bypasses BBB; low parenchymal pene- } \\
\text { tration }\end{array}$ & Witham et al., 1999 \\
\hline Intranasal delivery & $\begin{array}{l}\text { Agent is inhaled \& follows olfactory \& trigeminal nerve } \\
\text { pathways }\end{array}$ & da Fonseca et al., 2008 \& 2013 \\
\hline Gliadel wafer & Surgically implanted carmustine-loaded polymer & $\begin{array}{l}\text { Kunwar et al., 2010; Attenello et al., } \\
2008\end{array}$ \\
\hline Efflux pump inhibitors & $\begin{array}{l}\text { Suppress transporters to increase intraparenchymal } \\
\text { drug presence }\end{array}$ & Brown et al., 2008 \\
\hline $\begin{array}{l}\text { Focused ultrasound-mediated } \\
\text { disruption }\end{array}$ & Thermomechanical disruption of the BBB & None \\
\hline Molecular Trojan horses & $\begin{array}{l}\text { Engineered ligand coupled to drug of interest shuttled } \\
\text { across BBB via receptor-mediated transcytosis }\end{array}$ & Drappatz et al., 2013 \\
\hline Liposomal Trojan horses & $\begin{array}{l}\text { Lipophilic vehicle loaded w/ Tx agent for delivery } \\
\text { across BBB }\end{array}$ & Caraglia et al., 2006; Fabel et al., 2001 \\
\hline Nanoparticle vehicular delivery & $\begin{array}{l}\text { Nanoscale vehicular devices often delivered via CED \& } \\
\text { intrathecal or intraventricular injection }\end{array}$ & None \\
\hline Viral vector-mediated delivery & Vector for transport \& transduction of gene Tx & Rainov, 2000 \\
\hline Stem cell-mediated delivery & Cells serve as carriers $\mathrm{w} /$ tropism for cancer cells & None \\
\hline
\end{tabular}

CED = convection-enhanced delivery; IA = intraarterial; IL-2 = interleukin-2; INF $\gamma=$ interferon- $\gamma$; LTC4 = leukotriene C4; TNF- $\alpha=$ tumor necrosis factor $-\alpha$; Tx $=$ therapy.

Effectiveness of the RMP-7 and carboplatin regimen was investigated in Phase I (2001) and Phase II (2006) clinical trials, which concluded that this combination was ineffective. ${ }^{164,165}$ Recent research indicates that glioma invasion can be achieved through a bradykinin-mediated chemotactic process, ${ }^{112,144}$ and this finding questions the overall efficacy of using a kinin agent. Nevertheless, kinin agents continue to remain an active area of translational research ${ }^{46}$ particularly because of the advantage of preferential BTB disruption observed with these vasoactive compounds. ${ }^{57,83,109}$

\section{Hyperosmotic Disruption}

Transient hyperosmotic disruption of the BBB to facilitate its penetration involves the use of an interaarterially delivered osmotic agent, such as mannitol. Mannitol acts by drawing water from the intra- or extracellular compartments into the vasculature, effectively decreasing interstitial and intracellular cerebral volumes. This mechanism of BBB disruption may involve endothelial dehydration, cell body shriveling, and a resultant opening of the spaces between the tight junctions. ${ }^{114}$ This method was pioneered by Neuwelt and colleagues in $1979,{ }^{119}$ and the effectiveness of a $25 \%$ mannitol solution was investigated in clinical trials in $1981 .{ }^{120}$ Further analysis in rat models indicated that this disruption of the BBB is maintained for approximately 30 minutes $^{82,179}$ and that permeability is achieved for between 15 minutes and 4 hours, depending on the molecular weight of the agent used. Current in vivo research efforts involve intraarterial injection of the hyperosmotic agent that induces BBB disruption and subsequent intraarterial injection of the drug of interest. These approaches have indicated that the intraarterial route significantly improves BBB penetration compared with intravenous injection of the drug. ${ }^{35,74,117}$ Additionally, recent research indicated that volume, not flow rate, of the mannitol injection is an important factor influencing the magnitude of the BBB disruption. ${ }^{62}$ In addition to enhancing BBB permeability to drugs, use of mannitol in vivo has been shown to increase permeability of intraarterially injected viral vectors ${ }^{62,113}$ stem cells, ${ }^{70}$ liposomal vehicles, ${ }^{108}$ and antibodies such as $\mathrm{BV} .^{23}$

In addition to opening the BBB, mannitol may decrease intratumoral hydrostatic pressure, which may enhance chemotherapy delivery by passive diffusion. However, it is important to remember that although BBB disruption with mannitol has been demonstrated, the data about the success of in vivo BTB disruption with mannitol are conflicting. ${ }^{35,73,145,179}$ In addition, earlier research with mannitol has shown that it may preferentially permeate healthy BBB, 
thereby increasing neurotoxicity ${ }^{78,84}$ which is in contrast to the effects seen with vasoactive mediators..$^{57,83,109}$ Despite these observations, Phase I clinical trials with patients who had malignant gliomas have reported significant radiological evidence for tumor reduction and improved progression-free survival after mannitol-mediated BBB disruption followed by treatment with intraarterially injected BV and melphalan/carboplatin, respectively. ${ }^{23,74}$ In summary, these findings suggest that mannitol mediates BBB disruption in vitro and in vivo for certain tumors, but its efficacy is largely agent dependent. More research is necessary to determine the efficacy of mannitol as a method for delivering chemotherapy in GBM.

\section{Intraarterial Infusion}

Intraarterial infusion provides a more favorable approach for $\mathrm{BBB}$ penetration because this method avoids the limitations of systemic dilution and toxicity of chemotherapy agents. Initial use of intraarterial infusions for malignant tumors of the brain began in the 1950s following the identification of the BBB ${ }^{66}$ Recent research with intraarterial infusions has focused on $\mathrm{BV}$ because the VEGF plays an important role in cancer stem-like cell (CSC) signaling at the perivascular niche, the heterogeneity of which generates chemotherapeutic resistance of GBM. The perivascular niche, also described as the intratumoral neoangiogenic margin, is a microenvironment housing multiple cell types including CSCs. ${ }^{36}$ Importantly, CSCs secrete VEGF, and in GBM, the CSCs may differentiate into endothelial precursors, which in response to VEGF signaling can further differentiate into mature endothelial cells, leading to angiogenesis..$^{29,163}$ Therefore, perivascular inhibition of VEGF signaling by BV represents an important method for disrupting GBM progression by limiting the blood supply to CSCs. This may be achieved by selective intraarterial niche disruption by intraarterially infused $\mathrm{BV} .^{29}$ The BBB/BTB would maintain the highly regulated signaling environment in the perivascular niche by limiting drug exposure and retaining tumor-derived signaling molecules within this niche through the abovementioned processes. The upper pore size constraint of the BTB is approximately $12 \mathrm{~nm},{ }^{139}$ which necessitates barrier disruption to enable translocation of BV across the neurovascular complex and accumulation in the intratumoral signaling environment. ${ }^{29}$ This targeted translocation was achieved in a mouse model in which intraarterial infusion with BV resulted in significantly greater $\mathrm{BBB}$ penetration of the medication than with intravenous infusion; an even greater intratumoral BV presence was observed when intraarterial infusion was combined with mannitol injection. ${ }^{27}$ Burkhardt et al. ${ }^{28}$ also observed improved progression-free survival in a clinical trial with BV designed to investigate the effect of a single intraarterial infusion of BV followed by standard-of-care intravenous BV therapy to treat recurrent GBM.

Additional clinical trials have evaluated intraarterial injection of cisplatin, ${ }^{55}$ carboplatin, ${ }^{64,65,85,96}$ or methotrexate ${ }^{10,64,65,85}$ to treat additional CNS tumors, and many of these trials utilized BBB disruption with mannitol. To evaluate the use of intraarterial infusion as a single modality for GBM treatment, Theodotou et al. ${ }^{152}$ performed a literature review in 2014, which showed that although intraarterial chemotherapy for GBM was associated with lower median overall survival (14.02 months) than intravenous infusion (16.3 months), it decreased the risk of adverse side effects (1.08 and 1.54 recorded events per patient, respectively).

In summary, the efficacy and safety of intraarterial infusion for treating GBM has been extensively studied. These studies have indicated at best marginal efficacy compared with control treatments. However, as research expands to study newer therapies, intraarterial infusion will likely continue to have a role in providing BBB circumvention.

\section{Surgical Approaches}

Surgical circumvention of the BBB involves placing a pharmaceutical agent or eluting system directly into the tumor, brain, or CSF. These delivery agents include controlled-release medications (Gliadel), brachytherapy, intrathecal delivery, intraventricular delivery, intranasal delivery, or a catheter convection system for drug delivery.

Distribution of agents via convection-enhanced delivery involves microinfusions of an agent with micropumps for targeted delivery to the brain parenchyma, and this approach depends on hydrostatic pressures, diffusion, and efflux from the capillaries. ${ }^{73}$ Examples of delivery agents used are nanoparticles, liposomes, viral vectors, and immunotoxins. ${ }^{160}$ Convection systems, though intuitively attractive, result in heterogeneous distribution of these agents, impedingly high interstitial fluid pressure, rapid efflux from the injection site, ${ }^{118,128}$ and they may also result in neurotoxicity. ${ }^{43}$

A study by Sampson et al. ${ }^{138}$ showed that a bolus dose of stereotactic injection into GBM tumors provided no advantage in the distribution volume of chemotherapy agents compared with continuous bulk flow by convection-enhanced delivery. However, this delivery method has been shown to improve survival in a murine model of intratumoral etoposide ${ }^{146}$ and has mediated targeted GBM therapy with the immunotoxins DTAT and DTATEGF. ${ }^{80}$ Convection-enhanced delivery was not able to sufficiently deliver O-6-methylguanine-DNA methyltransferasesiRNA/liposome complexes to the brain in rat and porcine models because of a limited radial liposome distribution attributed to the cationic nature of these liposomes. ${ }^{157}$ However, this delivery method has been implemented in numerous clinical trials to assess the efficacy of using multiple chemotherapy agents to treat GBM. ${ }^{22,33,34,95,161,170}$ Recently, convection-enhanced delivery was implemented with a transcutaneous bone anchor port in an in vivo human trial of carboplatin for recurrent GBM; the results suggested use of the method in further clinical trials. ${ }^{12}$ In summary, convection-enhanced delivery is currently an active research frontier in the delivery of GBM therapy and will likely be implemented in clinical trials in the near future.

Approaches very similar to convection-enhanced delivery are intraventricular and intrathecal drug administrations into the CSF. These approaches are also dependent on bulk flow as the driving force for distribution within the leptomeningeal space, but do not rely on BBB or BCSFB penetration. Intraventricular dosing of chemotherapy for 
GBM has been previously studied. ${ }^{49}$ However, because this delivery route facilitates only very limited exposure of the parenchyma to chemotherapy agents, it is not effective for treating parenchymal disease. Moreover, the large volume of CSF turnover leads to significant diffusion-related declines in leptomeningeal drug concentrations. These factors make these modalities not feasible for treating intraparenchymal GBM.$^{73}$ However, in clinical trials, leptomeningeal drug concentrations have been shown to be high enough in brain diseases such as carcinomatous meningitis, meningeal gliomatosis, and lymphomatous meningitis whose treatments do not require parenchymal penetration of chemotherapy agents. ${ }^{123,173,185}$ Carcinomatous meningitis may co-occur with multiple systemic malignant tumors, in which case the leptomeningeal space serves as a safe haven for these tumors because of the $\mathrm{BBB}$, which shelters these tumors from exposure to systemic chemotherapy. ${ }^{44}$ The CSF in carcinomatous meningitis shows pleocytosis, elevated protein levels, and glycorrhachia, ${ }^{44}$ which likely are the result of the decreased control over permeability at the BCSFB. In carcinomatous meningitis, tumors may occupy the perivascular spaces and increase the interstitial compartment pressure, ${ }^{114}$ which limits solute translocation across the BBB, BCSFB, and CSF-parenchymal interface and therefore poses a challenge for treatment. In summary, therapies utilizing the CSF as a means to circumvent the $\mathrm{BBB} / \mathrm{BCSFB}$ are effective for leptomeningeal disease; however, restricted parenchymal exposure limits its clinical applicability for GBM therapy.

Intranasal delivery of chemotherapy has been hypothesized to result in sufficient concentrations of antineoplastic agents within parenchymal tumors. Clinical trials that have tested intranasal administration of perillyl alcohol to treat CNS tumors have indicated significant clinical tumor remission: a cohort composed of $>80 \%$ patients with GBM had a 4-year tumor remission rate of $19 \% .^{47,48}$ The chemotherapy agents translocate into the CNS via olfactory and trigeminal nerve pathways. ${ }^{76}$ In addition, intranasal delivery has been recently studied for the delivery of neural stem cells and curcumin-loaded, nanostructure lipid carriers and has shown good results in localizing to tumors. ${ }^{106,133}$ In summary, intranasal administration represents an under-researched method for circumventing the $\mathrm{BBB}$, and early clinical results suggest a potential role for this modality in future clinical trials.

An alternative to injectable chemotherapy agents is the Gliadel wafer. It represents an adjunctive method to surgery for localized chemotherapy delivery; the wafer consists of a surgically implanted, carmustine-loaded polymer for continuous dosing of a medication to a potentially neoplastic environment within a resection cavity. The chemotherapy delivery achieved with Gliadel relies on simple diffusion, falls off sharply within a few millimeters, and lacks precise control of the concentration-time exposure. ${ }^{73}$ Despite these drawbacks, a systematic literature review of 19 studies with 795 patients reported that using adjuvant Gliadel resulted in a mean survival of 16.2 months, whereas patients receiving the standard of care had a mean survival of approximately 14 months. ${ }^{25,149}$ This study also reported that use of Gliadel resulted in a $42.7 \%$ complication rate. ${ }^{25}$ However, a review of the outcomes in 1013 cranioto- mies for malignant astrocytoma in which 288 patients received Gliadel wafers observed no significant increase in perioperative complications compared with the standard of care. ${ }^{11}$ With only a marginal increase in survival and a potentially increased risk of complications, this therapy is at best only marginally indicated for treating GBM.

\section{Efflux Pump Inhibitors}

As discussed above, the cerebral endothelium and tumor cells possess a multitude of active efflux transporters ${ }^{6}$ which may transport compounds that have crossed the BBB back into the neurovascular system. Inhibitors to these transporters could conceivably increase the net flux across the BBB. The previously mentioned ATPdependent ABCB1 (P-glycoprotein) transporter actively pumps chemotherapy agents such as methotrexate, vinca alkaloids, anthracycline analogs, various monoclonal antibodies, and TMZ out of neoplastic and endothelial cells and into the vascular lumen.6,116 Upregulation of the MDR1/ABCG2 transporter contributes to tumor resistance against TMZ. ${ }^{135}$ The proposed mechanism involves a TMZ-induced, active-state conformational change in the MDR1 protein, which generates signaling via epidermal growth factor that serves as an autocrine stimulator of GBM cells to induce expression of the $M D R l$ gene. ${ }^{116}$ The expanding recognition of the role of efflux transporters in chemoresistance suggests that modulating their function could be an appealing strategy in chemotherapy.

One such molecular modulator is erlotinib, an inhibitor of epidermal growth factor receptor kinase. Using a mouse model, investigators have shown that erlotinib prevents TMZ-induced, MDR1-mediated tumor resistance. ${ }^{116}$ However, this finding was not replicated in a clinical trial, which indicated that adding erlotinib to TMZ therapy did not increase survival of patients with GBM. ${ }^{26}$ The P-glycoprotein is also the target of an inhibitor, PSC-833 (valspodar), application of which resulted in an increased permeability of the BBB to the chemotherapy agent litaxel and in a $90 \%$ reduction in GBM volume in a xenograft mouse model. ${ }^{61}$ The scarcity of research into this modality reflects the complex milieu of efflux pumps involved in the $\mathrm{BTB} / \mathrm{BBB}$ function and the cost involved in the development of these target-specific agents.

\section{Thermotherapy}

Thermotherapy can encompass many modalities for producing changes to the $\mathrm{BBB}$ and to the tumor mass. They include focused ultrasound, radiofrequency microwaves, laser-induced interstitial thermotherapy, and magnetic disruption. ${ }^{99}$ These modalities induce intracranial hyperthermia, which facilitates potentiation of radiotherapy and chemotherapy, exhibits preferential cytotoxicity to glioma cells, increases BBB permeability, and induces heat-shock protein-mediated cytotoxicity within tumor cells. ${ }^{99,167}$ Most relevant to this discussion is focused ultrasound-mediated disruption of the $\mathrm{BBB}$, which is appealing because it is noninvasive and economical to perform. Focused ultrasound thermomechanically disrupts the BBB. A decrease in ultrasonic intensity coupled with intravenous injection of albumin-coated octafluoropropane 
microbubbles produces only a transient opening of the $\mathrm{BBB}$, which decreases the risk for permanent tissue damage ${ }^{81,92}$ The microbubbles enhance the thermal effects of the ultrasonic energy and decrease the ultrasonic intensity required for disruption of the BBB. ${ }^{81}$ Refinement of this process has facilitated a protocol for reliable BBB disruption, and no histological or functional evidence has suggested any damage in vivo in nonhuman primates. ${ }^{110}$

In animal models, ultrasound-mediated disruption has delivered several agents across the BBB, including trastuzumab, ${ }^{90} \mathrm{TMZ},{ }^{168}$ doxorubicin, ${ }^{93,155}$ poly (ethylene glycol)poly (lactic acid) nanoparticles, ${ }^{182}$ AP-1 lipoplatin, ${ }^{177}$ and self-complementary adeno-associated virus. ${ }^{153}$ The upper size limit for transfer across the BBB through focused ultrasound is $2000 \mathrm{kD},{ }^{38,42}$ large enough to facilitate transfer of a multitude of therapeutic agents. Notably, experiments in a rat model reported a $38.6 \%$ CSF-to-plasma ratio for TMZ transferred with focused ultrasound compared with only $22.7 \%$ in control modalities. ${ }^{168}$ Disruption of the BBB via ultrasound exhibits sufficient translational research success to warrant further evaluation of this delivery method in clinical trials.

\section{Vehicular Delivery Devices}

Vehicular delivery can serve as a stand-alone or adjuvant method for improved delivery of chemotherapy, gene therapy, or gene-silencing RNA across the BBB. The first 2 delivery methods have been called Trojan horses-one relies on molecular targeting and the other on lipophilic features to cross the BBB. Lastly, nanoparticle and viral vector vehicles will be discussed in the context of gene therapy.

Antibodies that facilitate transcytosis of carrier molecules have been called molecular Trojan horses. ${ }^{19}$ Using imaging data in a nonhuman primate model, researchers have shown that molecular Trojan horse-mediated recombinant protein transport was effective for translocating antibodies across the BBB. ${ }^{19}$ A study by Farrington et al. ${ }^{60}$ involved a therapeutic antibody possessing a previously described BBB-transcytosing arm called $\mathrm{FC} 5,{ }^{4}$ and a bivalent therapeutic arm fused with the human Fc protein. This antibody increased transfer of 2 natively impermeable molecules, neuropeptide $\mathrm{Y}$ and neuropeptide dalargin, 30 -fold across the BBB. ${ }^{60}$ The FC5 antibody targets the epitopes of the BBB-enriched transporter, and this targeting facilitates receptor-mediated transcytosis. ${ }^{4}$ The low-density lipoprotein receptor-related protein-1 was the target in a Phase I clinical trial for recurrent malignant GBM in which GRN1005, a peptide drug conjugate with paclitaxel, yielded sufficient results to warrant further investigation in Phase II trials. ${ }^{54}$ Other targets also have been used in molecular Trojan horse approaches, such as the transferrin, ${ }^{21,184}$ glutathione, ${ }^{16}$ and insulin receptors. ${ }^{20,21}$ However, these targets are less BBB specific and therefore less effective at enhancing BBB permeability. The molecular Trojan horse method was recently investigated for RNA interference via transferrin receptor targeting to gliomas. ${ }^{184}$ The molecular Trojan horse approach enables very target-specific focal delivery of recombinant therapy, but a more diffusely dispersed Trojan horse method involves a liposomal vehicle.
The second class of Trojan horse devices involves liposomal vehicles, termed liposomal Trojan horses. These vehicles possess a highly lipophilic character and are therefore more efficient at penetrating the BBB; accordingly, liposomes may be used to deliver agents that cannot cross the BBB to their intraparenchymal targets and help maintain a controlled release of chemotherapy or genetherapy agents. ${ }^{186}$ Liposomal Trojan horse-mediated passage across the BBB was first described in $1980,{ }^{129}$ and since then, it has been extensively researched for pharmaceutical delivery. The liposomal Trojan horse approach to test efficacy of delivery in treating GBM has been applied in many animal models such as canine, ${ }^{94}$ rat, ${ }^{94,136,176}$ and nonhuman primate models. ${ }^{137}$ Two clinical trials with liposome-loaded doxorubicin for treatment of solid tumor metastasi $^{32}$ and malignant glioma ${ }^{59}$ reported more successful outcomes than in a control treatment, although in the glioma trial, the median overall survival with the standard of care exceeded that of the liposome-loaded approach. We also note that much of the recent research into liposomal vehicles has focused on its application in gene therapy.

The use of nanoparticles involves a delivery concept similar to that of liposomal Trojan horses, except the method of BBB circumvention involves simple diffusion from a convection-enhanced delivery, intraventricular, or intrathecal source. Experiments in animal models have shown that nanoparticles improved in vivo trafficking of chemotherapy agents, such as camptothecin, TMZ, doxorubicin, irinotectan, and vincristine ${ }^{14,141,154}$ and also of gene-therapy agents. ${ }^{101}$ Nanoparticle-based approaches can uniquely serve in targeted thermotherapy, for example, via stereotactically injecting magnetic nanoparticles and inducing particle vibration via MRI.${ }^{99}$ This field represents a novel approach to vehicular delivery of chemotherapy with promise for future research and clinical trials.

Vehicular delivery has now expanded to include gene therapy as a cargo. Current research has shown that adenovirus, ${ }^{31,159}$ adeno-associated virus, ${ }^{41,77,91}$ vesicular stomatitis virus, ${ }^{126}$ retrovirus, ${ }^{130}$ herpes simplex virus, ${ }^{130}$ liposomal Trojan horses, ${ }^{89,180,181}$ Semliki Forest virus, ${ }^{134}$ and synthetic nanoparticles ${ }^{101}$ can all be used as vehicles for BBB transit. Expansion of gene-therapy approaches to treat neurological disease has included the use of viral vectors for GBM therapy. However, viral vectors, although efficient and customizable by tropism and replication method, are problematic because they may pose a risk for catastrophic immunogenic responses and may not effectively reach tumor cells that have disseminated throughout the brain parenchyma. ${ }^{186}$

The side effects of viral vectors have led to greater adoption of synthetic delivery systems, as described above, such as liposomal Trojan horses and nanoparticle-mediated delivery for gene therapy. The advantages of these synthetic delivery systems are that they target tumor cells and can carry large genetic payloads. In addition, many of these delivery methods elicit little or no immune response, ${ }^{186}$ making them ideal vehicles for DNA and siRNA transfer. Initial synthetic systems for gene therapy had excessive cationic density and induced significant toxicity by disrupting normal cell functioning. ${ }^{105,156}$ In light of these findings, studies with high-molecular weight hydrophobic 
compounds with lower cationic densities have yielded a polymer vehicle with minimal adverse effects from in vivo exposure. ${ }^{186}$

Uses of molecular and liposomal Trojan horses, viral vectors, and nanoparticles have involved combinations with hyperosmolar disruption, convection-enhanced delivery, ${ }^{134,162}$ receptor-mediated substrate tagging, ${ }^{97}$ and ultrasound-mediated BBB disruption ${ }^{177,182}$ to provide even better circumvention of the BBB. Results have shown that protocols that combine different delivery modalities statistically significantly improve the penetration of the BBB. ${ }^{177,178,182}$ The efficacy of an approach consisting of a liposome-based, focused ultrasound-assisted approach to open the BBB was measured via dynamic microSPECT/ CT imaging of ${ }^{111}$ In-labeled liposomes containing doxorubicin. ${ }^{178}$ This approach yielded maximal doxorubicin concentrations with focused ultrasound-assisted BBB disruption that were twice those of a control treatment in a mouse model of GBM. ${ }^{178}$

In summary, vehicular delivery for BBB circumvention represents another research frontier and provides a targeted delivery mechanism with application for delivery of many GBM therapies. It also highlights the need for further research into how the aforementioned methods could be further combined to optimize synthetic vehicular delivery across the BBB.

\section{Stem Cell-Mediated Delivery of Therapies}

The principle of stem cell-mediated chemotherapy delivery is similar to that of viral vectors. The tropism of the stem cells toward cancer cells may facilitate targeted delivery of chemotherapy, gene therapy, prodrugs, or siRNA agents to brain tumors. Researchers have largely focused on mesenchymal stem cells as delivery agents because of the lack of allogeneic barriers to therapy and because neural stem cells require an autologous source. ${ }^{8}$ Stem cell-based approaches fuel active research in a number of fields, including neurotrauma, neurodegenerative diseases, and neurooncology. The tumor-homing ability of the mesenchymal stem cells is the driving force, indicating their potential utility in glioma diagnosis and therapy. ${ }^{53,131}$ It has been suggested that selecting the mesenchymal stem cells for the presence of specific chemokine receptors could enable control of their homing capability. ${ }^{183}$

The use of mesenchymal stem cells in GBM has included delivery of gene therapy in murine $e^{9,56}$ and canine ${ }^{175}$ hosts, as well as delivery of synthetic miRNAs in vitro ${ }^{98}$ and in a murine system. ${ }^{115}$ Neural stem cells have been used to deliver lanatoside $\mathrm{C}$ in a murine host with a xenograft human GBM $^{151}$ and for delivery of carboxylesteraseactivated CPT-11 (irinotecan) therapy to xenograft human glioma: ${ }^{111}$ both approaches showed therapeutic efficacy and feasibility. In combination, the results from these studies suggest a progression of stem cell-assisted delivery of chemotherapy in experimental models to the clinical trial stage for GBM treatment.

However, we note some reservation about stem cellmediated delivery because it has been associated with tumor formation and increased neuroinflammation, despite the innate immunosuppressive character of stem cells. ${ }^{79}$ It has also been reported that mesenchymal stem cells may support the tumors that they are targeting for therapy. ${ }^{72}$ Despite these challenges, mesenchymal stem cell therapy is being investigated in clinical trials for many diseases, including cancers of the ovary, prostate, and head and neck, as well as for hematological cancers. ${ }^{8}$ Stem cell-assisted chemotherapy may therefore offer a viable clinical option for treating some CNS tumors after the efficacy and safety of this approach have been established in human subjects.

\section{Conclusions}

The BBB serves an essential function in the CNS, but its presence necessitates complex therapeutic solutions for treating malignant tumors of the CNS. In this review, we have discussed several current, theoretical, and animalmodel methods for circumventing this obstacle to chemotherapy. In view of the high morbidity and mortality rates associated with GBM, many promising methods for its treatment have emerged from years of laboratory research to address the impediments to improved BBB permeability. By targeting the physiological processes at the $\mathrm{BBB}$ or at the BTB, research into these new methods and techniques has provided the groundwork for future combinatory therapies and removed hurdles to administering therapeutic agents that were previously ineffective in treating CNS tumors. Researchers and clinicians have great hope that these evolving techniques will contribute to a more effective standard of care for patients with GBM.

\section{References}

1. Abbott NJ: Astrocyte-endothelial interactions and bloodbrain barrier permeability. J Anat 200:629-638, 2002

2. Abbott NJ: Blood-brain barrier structure and function and the challenges for CNS drug delivery. J Inherit Metab Dis 36:437-449, 2013

3. Abbott NJ, Rönnbäck L, Hansson E: Astrocyte-endothelial interactions at the blood-brain barrier. Nat Rev Neurosci 7:41-53, 2006

4. Abulrob A, Sprong H, Van Bergen en Henegouwen P, Stanimirovic D: The blood-brain barrier transmigrating single domain antibody: mechanisms of transport and antigenic epitopes in human brain endothelial cells. J Neurochem 95:1201-1214, 2005

5. Acerbi F, Broggi M, Eoli M, Anghileri E, Cavallo C, Boffano $\mathrm{C}$, et al: Is fluorescein-guided technique able to help in resection of high-grade gliomas? Neurosurg Focus 36:E5, 2014

6. Agarwal S, Sane R, Oberoi R, Ohlfest JR, Elmquist WF: Delivery of molecularly targeted therapy to malignant glioma, a disease of the whole brain. Expert Rev Mol Med 13:e17, 2011

7. Agarwala SS, Kirkwood JM: Temozolomide, a novel alkylating agent with activity in the central nervous system, may improve the treatment of advanced metastatic melanoma. Oncologist 5:144-151, 2000

8. Aleynik A, Gernavage KM, Mourad YSh, Sherman LS, Liu K, Gubenko YA, et al: Stem cell delivery of therapies for brain disorders. Clin Transl Med 3:24, 2014

9. Altanerova V, Cihova M, Babic M, Rychly B, Ondicova K, Mravec B, et al: Human adipose tissue-derived mesenchymal stem cells expressing yeast cytosinedeaminase:uracil phosphoribosyltransferase inhibit intracerebral rat glioblastoma. Int J Cancer 130:2455-2463, 2012 
10. Angelov L, Doolittle ND, Kraemer DF, Siegal T, Barnett GH, Peereboom DM, et al: Blood-brain barrier disruption and intra-arterial methotrexate-based therapy for newly diagnosed primary CNS lymphoma: a multi-institutional experience. J Clin Oncol 27:3503-3509, 2009

11. Attenello FJ, Mukherjee D, Datoo G, McGirt MJ, Bohan E, Weingart JD, et al: Use of Gliadel (BCNU) wafer in the surgical treatment of malignant glioma: a 10-year institutional experience. Ann Surg Oncol 15:2887-2893, 2008

12. Barua NU, Hopkins K, Woolley M, O’Sullivan S, Harrison R, Edwards RJ, et al: A novel implantable catheter system with transcutaneous port for intermittent convection-enhanced delivery of carboplatin for recurrent glioblastoma. Drug Deliv [epub ahead of print], 2014

13. Becker KP, Yu J: Status quo-standard-of-care medical and radiation therapy for glioblastoma. Cancer J 18:12-19, 2012

14. Bernal GM, LaRiviere MJ, Mansour N, Pytel P, Cahill KE, Voce DJ, et al: Convection-enhanced delivery and in vivo imaging of polymeric nanoparticles for the treatment of malignant glioma. Nanomedicine (Lond Print) 10:149-157, 2014

15. Betz AL: Transport of ions across the blood-brain barrier. Fed Proc 45:2050-2054, 1986

16. Birngruber T, Raml R, Gladdines W, Gatschelhofer C, Gander E, Ghosh A, et al: Enhanced doxorubicin delivery to the brain administered through glutathione PEGylated liposomal doxorubicin (2B3-101) as compared with generic Caelyx, ${ }^{\circledR /}$ Doxil $^{\circledR}$ - a cerebral open flow microperfusion pilot study. J Pharm Sci 103:1945-1948, 2014

17. Black KL, Chio CC: Increased opening of blood-tumour barrier by leukotriene $\mathrm{C} 4$ is dependent on size of molecules. Neurol Res 14:402-404, 1992

18. Black P, Hand CM, Vender JR, Finkelstein SD: Chemotherapy in experimental brain tumor, part 2: pretreatment with leukotriene C4 prolongs survival. J Neurooncol 36:7-19, 1998

19. Boado RJ, Hui EK, Lu JZ, Sumbria RK, Pardridge WM: Blood-brain barrier molecular trojan horse enables imaging of brain uptake of radioiodinated recombinant protein in the rhesus monkey. Bioconjug Chem 24:1741-1749, 2013

20. Boado RJ, Lu JZ, Hui EK, Sumbria RK, Pardridge WM: Pharmacokinetics and brain uptake in the rhesus monkey of a fusion protein of arylsulfatase a and a monoclonal antibody against the human insulin receptor. Biotechnol Bioeng 110:1456-1465, 2013

21. Boado RJ, Pardridge WM: Comparison of blood-brain barrier transport of glial-derived neurotrophic factor (GDNF) and an IgG-GDNF fusion protein in the rhesus monkey. Drug Metab Dispos 37:2299-2304, 2009

22. Bogdahn U, Hau P, Stockhammer G, Venkataramana NK, Mahapatra AK, Suri A, et al: Targeted therapy for high-grade glioma with the TGF- $\beta 2$ inhibitor trabedersen: results of a randomized and controlled phase IIb study. Neuro Oncol 13:132-142, 2011

23. Boockvar JA, Tsiouris AJ, Hofstetter CP, Kovanlikaya I, Fralin S, Kesavabhotla K, et al: Safety and maximum tolerated dose of superselective intraarterial cerebral infusion of bevacizumab after osmotic blood-brain barrier disruption for recurrent malignant glioma. Clinical article. J Neurosurg 114:624-632, 2011

24. Breedveld P, Beijnen JH, Schellens JH: Use of P-glycoprotein and BCRP inhibitors to improve oral bioavailability and CNS penetration of anticancer drugs. Trends Pharmacol Sci 27:17-24, 2006

25. Bregy A, Shah AH, Diaz MV, Pierce HE, Ames PL, Diaz $\mathrm{D}$, et al: The role of Gliadel wafers in the treatment of highgrade gliomas. Expert Rev Anticancer Ther 13:1453-1461, 2013

26. Brown PD, Krishnan S, Sarkaria JN, Wu W, Jaeckle KA,
Uhm JH, et al: Phase I/II trial of erlotinib and temozolomide with radiation therapy in the treatment of newly diagnosed glioblastoma multiforme: North Central Cancer Treatment Group Study N0177. J Clin Oncol 26:5603-5609, 2008

27. Burkhardt JK, Hofstetter CP, Santillan A, Shin BJ, Foley $\mathrm{CP}$, Ballon DJ, et al: Orthotopic glioblastoma stem-like cell xenograft model in mice to evaluate intra-arterial delivery of bevacizumab: from bedside to bench. J Clin Neurosci 19:1568-1572, 2012

28. Burkhardt JK, Riina H, Shin BJ, Christos P, Kesavabhotla $\mathrm{K}$, Hofstetter CP, et al: Intra-arterial delivery of bevacizumab after blood-brain barrier disruption for the treatment of recurrent glioblastoma: progression-free survival and overall survival. World Neurosurg 77:130-134, 2012

29. Burkhardt JK, Riina HA, Shin BJ, Moliterno JA, Hofstetter CP, Boockvar JA: Intra-arterial chemotherapy for malignant gliomas: a critical analysis. Interv Neuroradiol 17:286-295, 2011

30. Burkhardt JK, Santillan A, Hofstetter CP, Christos P, Berry $\mathrm{N}$, Shin BJ, et al: Intra-arterial bevacizumab with blood brain barrier disruption in a glioblastoma xenograft model. J Exp Ther Oncol 10:31-37, 2012

31. Candolfi M, Xiong W, Yagiz K, Liu C, Muhammad AK, Puntel M, et al: Gene therapy-mediated delivery of targeted cytotoxins for glioma therapeutics. Proc Natl Acad Sci U S A 107:20021-20026, 2010

32. Caraglia M, Addeo R, Costanzo R, Montella L, Faiola V, Marra M, et al: Phase II study of temozolomide plus pegylated liposomal doxorubicin in the treatment of brain metastases from solid tumours. Cancer Chemother Pharmacol 57:34-39, 2006

33. Carpentier A, Laigle-Donadey F, Zohar S, Capelle L, Behin A, Tibi A, et al: Phase 1 trial of a $\mathrm{CpG}$ oligodeoxynucleotide for patients with recurrent glioblastoma. Neuro Oncol 8:6066, 2006

34. Carpentier A, Metellus P, Ursu R, Zohar S, Lafitte F, Barrié $\mathrm{M}$, et al: Intracerebral administration of $\mathrm{CpG}$ oligonucleotide for patients with recurrent glioblastoma: a phase II study. Neuro Oncol 12:401-408, 2010

35. Charest G, Sanche L, Fortin D, Mathieu D, Paquette B: Optimization of the route of platinum drugs administration to optimize the concomitant treatment with radiotherapy for glioblastoma implanted in the Fischer rat brain. J Neurooncol 115:365-373, 2013

36. Charles N, Holland EC: The perivascular niche microenvironment in brain tumor progression. Cell Cycle 9:3012-3021, 2010

37. Chauffert B, Feuvret L, Bonnetain F, Taillandier L, Frappaz $\mathrm{D}$, Taillia H, et al: Randomized phase II trial of irinotecan and bevacizumab as neo-adjuvant and adjuvant to temozolomide-based chemoradiation compared with temozolomidechemoradiation for unresectable glioblastoma: final results of the TEMAVIR study from ANOCEF. Ann Oncol 25:14421447,2014

38. Chen H, Konofagou EE: The size of blood-brain barrier opening induced by focused ultrasound is dictated by the acoustic pressure. J Cereb Blood Flow Metab 34:11971204,2014

39. Cheng L, Bao S, Rich JN: Potential therapeutic implications of cancer stem cells in glioblastoma. Biochem Pharmacol 80:654-665, 2010

40. Cheng L, Huang Z, Zhou W, Wu Q, Donnola S, Liu JK, et al: Glioblastoma stem cells generate vascular pericytes to support vessel function and tumor growth. Cell 153:139-152, 2013

41. Chiu TL, Lin SZ, Hsieh WH, Peng CW: AAV2-mediated interleukin-12 in the treatment of malignant brain tumors through activation of NK cells. Int J Oncol 35:1361-1367, 2009

42. Choi JJ, Wang S, Tung YS, Morrison B III, Konofagou EE: 
Molecules of various pharmacologically-relevant sizes can cross the ultrasound-induced blood-brain barrier opening in vivo. Ultrasound Med Biol 36:58-67, 2010

43. Ciordia R, Supko J, Gatineau M, Batchelor T: Cytotoxic chemotherapy: advances in delivery, pharmacology, and testing. Curr Oncol Rep 2:445-453, 2000

44. Clarke JL: Leptomeningeal metastasis from systemic cancer. Continuum (Minneap Minn) 18:328-342, 2012

45. Cloughesy TF, Black KL: Pharmacological blood-brain barrier modification for selective drug delivery. J Neurooncol 26:125-132, 1995

46. Côté J, Bovenzi V, Savard M, Dubuc C, Fortier A, Neugebauer W, et al: Induction of selective blood-tumor barrier permeability and macromolecular transport by a biostable kinin B1 receptor agonist in a glioma rat model. PLoS ONE 7:e37485, 2012

47. da Fonseca CO, Schwartsmann G, Fischer J, Nagel J, Futuro D, Quirico-Santos T, et al: Preliminary results from a phase I/II study of perillyl alcohol intranasal administration in adults with recurrent malignant gliomas. Surg Neurol 70:259-267, 2008

48. da Fonseca CO, Teixeira RM, Silva JC, DE Saldanha DA Gama Fischer J, Meirelles OC, Landeiro JA, et al: Long-term outcome in patients with recurrent malignant glioma treated with Perillyl alcohol inhalation. Anticancer Res 33:56255631,2013

49. Dakhil S, Ensminger W, Kindt G, Niederhuber J, Chandler W, Greenberg H, et al: Implanted system for intraventricular drug infusion in central nervous system tumors. Cancer Treat Rep 65:401-411, 1981

50. de Groot J, Sontheimer H: Glutamate and the biology of gliomas. Glia 59:1181-1189, 2011

51. Deo AK, Theil FP, Nicolas JM: Confounding parameters in preclinical assessment of blood-brain barrier permeation: an overview with emphasis on species differences and effect of disease states. Mol Pharm 10:1581-1595, 2013

52. Di Ieva A, Grizzi F, Sherif C, Matula C, Tschabitscher M: Angioarchitectural heterogeneity in human glioblastoma multiforme: a fractal-based histopathological assessment. Microvasc Res 81:222-230, 2011

53. Dietrich J, Imitola J, Kesari S: Mechanisms of disease: the role of stem cells in the biology and treatment of gliomas. Nat Clin Pract Oncol 5:393-404, 2008

54. Drappatz J, Brenner A, Wong ET, Eichler A, Schiff D, Groves MD, et al: Phase I study of GRN1005 in recurrent malignant glioma. Clin Cancer Res 19:1567-1576, 2013

55. Dropcho EJ, Rosenfeld SS, Vitek J, Guthrie BL, Morawetz RB: Phase II study of intracarotid or selective intracerebral infusion of cisplatin for treatment of recurrent anaplastic gliomas. J Neurooncol 36:191-198, 1998

56. Duebgen M, Martinez-Quintanilla J, Tamura K, Hingtgen S, Redjal N, Wakimoto H, et al: Stem cells loaded with multimechanistic oncolytic herpes simplex virus variants for brain tumor therapy. J Natl Cancer Inst 106:dju090, 2014

57. Elliott PJ, Hayward NJ, Dean RL, Blunt DG, Bartus RT: Intravenous RMP-7 selectively increases uptake of carboplatin into rat brain tumors. Cancer Res 56:3998-4005, 1996

58. Erdlenbruch B, Schinkhof C, Kugler W, Heinemann DE, Herms J, Eibl H, et al: Intracarotid administration of shortchain alkylglycerols for increased delivery of methotrexate to the rat brain. Br J Pharmacol 139:685-694, 2003

59. Fabel K, Dietrich J, Hau P, Wismeth C, Winner B, Przywara $\mathrm{S}$, et al: Long-term stabilization in patients with malignant glioma after treatment with liposomal doxorubicin. Cancer 92:1936-1942, 2001

60. Farrington GK, Caram-Salas N, Haqqani AS, Brunette E, Eldredge J, Pepinsky B, et al: A novel platform for engineering blood-brain barrier-crossing bispecific biologics. FASEB J 28:4764-4778, 2014

61. Fellner S, Bauer B, Miller DS, Schaffrik M, Fankhänel
M, Spruss T, et al: Transport of paclitaxel (Taxol) across the blood-brain barrier in vitro and in vivo. J Clin Invest 110:1309-1318, 2002

62. Foley CP, Rubin DG, Santillan A, Sondhi D, Dyke JP, Pierre Gobin Y, et al: Intra-arterial delivery of AAV vectors to the mouse brain after mannitol mediated blood brain barrier disruption. J Control Release 196:71-78, 2014

63. Ford J, Osborn C, Barton T, Bleehen NM: A phase I study of intravenous RMP-7 with carboplatin in patients with progression of malignant glioma. Eur J Cancer 34:1807-1811, 1998

64. Fortin D, Desjardins A, Benko A, Niyonsega T, Boudrias M: Enhanced chemotherapy delivery by intraarterial infusion and blood-brain barrier disruption in malignant brain tumors: the Sherbrooke experience. Cancer 103:2606-2615, 2005

65. Fortin D, Gendron C, Boudrias M, Garant MP: Enhanced chemotherapy delivery by intraarterial infusion and bloodbrain barrier disruption in the treatment of cerebral metastasis. Cancer 109:751-760, 2007

66. French JD, West PM, Von Amerongen FK, Magoun HW: Effects of intracarotid administration of nitrogen mustard on normal brain and brain tumors. J Neurosurg 9:378-389, 1952

67. Fry M, Ferguson AV: The sensory circumventricular organs: brain targets for circulating signals controlling ingestive behavior. Physiol Behav 91:413-423, 2007

68. Ghersi-Egea JF, Finnegan W, Chen JL, Fenstermacher JD: Rapid distribution of intraventricularly administered sucrose into cerebrospinal fluid cisterns via subarachnoid velae in rat. Neuroscience 75:1271-1288, 1996

69. Goldwirt L, Beccaria K, Carpentier A, Farinotti R, Fernandez C: Irinotecan and temozolomide brain distribution: a focus on ABCB1. Cancer Chemother Pharmacol 74:185-193, 2014

70. Gonzales-Portillo GS, Sanberg PR, Franzblau M, GonzalesPortillo C, Diamandis T, Staples M, et al: Mannitol-enhanced delivery of stem cells and their growth factors across the blood-brain barrier. Cell Transplant 23:531-539, 2014

71. Grant R, Walker M, Hadley D, Barton T, Osborn C: Imaging response to chemotherapy with RMP-7 and carboplatin in malignant glioma: size matters but speed does not. J Neurooncol 57:241-245, 2002

72. Greco SJ, Rameshwar P: Mesenchymal stem cells in drug/ gene delivery: implications for cell therapy. Ther Deliv 3:997-1004, 2012

73. Groothuis DR: The blood-brain and blood-tumor barriers: a review of strategies for increasing drug delivery. Neuro Oncol 2:45-59, 2000

74. Guillaume DJ, Doolittle ND, Gahramanov S, Hedrick NA, Delashaw JB, Neuwelt EA: Intra-arterial chemotherapy with osmotic blood-brain barrier disruption for aggressive oligodendroglial tumors: results of a phase I study. Neurosurgery 66:48-58, 2010

75. Gutman M, Laufer R, Eisenthal A, Goldman G, Ravid A, Inbar M, et al: Increased microvascular permeability induced by prolonged interleukin- 2 administration is attenuated by the oxygen-free-radical scavenger dimethylthiourea. Cancer Immunol Immunother 43:240-244, 1996

76. Hanson LR, Frey WH II: Intranasal delivery bypasses the blood-brain barrier to target therapeutic agents to the central nervous system and treat neurodegenerative disease. BMC Neurosci 9 (Suppl 3):S5, 2008

77. Harding TC, Lalani AS, Roberts BN, Yendluri S, Luan B, Koprivnikar KE, et al: AAV serotype 8-mediated gene delivery of a soluble VEGF receptor to the CNS for the treatment of glioblastoma. Mol Ther 13:956-966, 2006

78. Hiesiger EM, Voorhies RM, Basler GA, Lipschutz LE, Posner JB, Shapiro WR: Opening the blood-brain and bloodtumor barriers in experimental rat brain tumors: the effect of intracarotid hyperosmolar mannitol on capillary permeability and blood flow. Ann Neurol 19:50-59, 1986 
79. Horn AP, Bernardi A, Luiz Frozza R, Grudzinski PB, Hoppe JB, de Souza LF, et al: Mesenchymal stem cell-conditioned medium triggers neuroinflammation and reactive species generation in organotypic cultures of rat hippocampus. Stem Cells Dev 20:1171-1181, 2011

80. Huang J, Yuan D, Liu D, Li J, Li Y, Hall WA, et al: Efficacy of antiangiogenic targeted immunotoxin DTAT and DTATEGF against glioblastoma multiforme. Zhong Nan Da Xue Xue Bao Yi Xue Ban 39:1-5, 2014

81. Hynynen K, McDannold N, Vykhodtseva N, Jolesz FA: Noninvasive MR imaging-guided focal opening of the blood-brain barrier in rabbits. Radiology 220:640-646, 2001

82. Ikeda M, Nagashima T, Bhattacharjee AK, Kondoh T, Kohmura E, Tamaki N: Quantitative analysis of hyperosmotic and hypothermic blood-brain barrier opening. Acta Neurochir Suppl 86:559-563, 2003

83. Inamura T, Black KL: Bradykinin selectively opens bloodtumor barrier in experimental brain tumors. J Cereb Blood Flow Metab 14:862-870, 1994

84. Inoue T, Fukui M, Nishio S, Kitamura K, Nagara H: Hyperosmotic blood-brain barrier disruption in brains of rats with an intracerebrally transplanted RG-C6 tumor. J Neurosurg 66:256-263, 1987

85. Jahnke K, Kraemer DF, Knight KR, Fortin D, Bell S, Doolittle ND, et al: Intraarterial chemotherapy and osmotic blood-brain barrier disruption for patients with embryonal and germ cell tumors of the central nervous system. Cancer 112:581-588, 2008

86. Jain RK, Munn LL, Fukumura D: Dissecting tumour pathophysiology using intravital microscopy. Nat Rev Cancer 2:266-276, 2002

87. Jiang G, Jiang AJ, Xin Y, Li LT, Cheng Q, Zheng JN: Progression of $\mathrm{O}^{6}$-methylguanine-DNA methyltransferase and temozolomide resistance in cancer research. Mol Biol Rep 41:6659-6665, 2014

88. Johanson CE, Duncan JA III, Klinge PM, Brinker T, Stopa EG, Silverberg GD: Multiplicity of cerebrospinal fluid functions: new challenges in health and disease. Cerebrospinal Fluid Res 5:10, 2008

89. Kato T, Natsume A, Toda H, Iwamizu H, Sugita T, Hachisu $\mathrm{R}$, et al: Efficient delivery of liposome-mediated MGMTsiRNA reinforces the cytotoxity of temozolomide in GBMinitiating cells. Gene Ther 17:1363-1371, 2010

90. Kinoshita M, McDannold N, Jolesz FA, Hynynen K: Noninvasive localized delivery of Herceptin to the mouse brain by MRI-guided focused ultrasound-induced bloodbrain barrier disruption. Proc Natl Acad Sci U S A 103:11719-11723, 2006

91. Koerber JT, Klimczak R, Jang JH, Dalkara D, Flannery JG, Schaffer DV: Molecular evolution of adeno-associated virus for enhanced glial gene delivery. Mol Ther 17:2088-2095, 2009

92. Konofagou EE: Optimization of the ultrasound-induced blood-brain barrier opening. Theranostics 2:1223-1237, 2012

93. Kovacs Z, Werner B, Rassi A, Sass JO, Martin-Fiori E, Bernasconi M: Prolonged survival upon ultrasoundenhanced doxorubicin delivery in two syngenic glioblastoma mouse models. J Control Release 187:74-82, 2014

94. Krauze MT, Noble CO, Kawaguchi T, Drummond D, Kirpotin DB, Yamashita Y, et al: Convection-enhanced delivery of nanoliposomal CPT-11 (irinotecan) and PEGylated liposomal doxorubicin (Doxil) in rodent intracranial brain tumor xenografts. Neuro Oncol 9:393-403, 2007

95. Kunwar S, Chang S, Westphal M, Vogelbaum M, Sampson J, Barnett G, et al: Phase III randomized trial of CED of IL13-PE38QQR vs Gliadel wafers for recurrent glioblastoma. Neuro Oncol 12:871-881, 2010
96. Larner JM, Phillips CD, Dion JE, Jensen ME, Newman SA, Jane JA: A phase 1-2 trial of superselective carboplatin, low-dose infusional 5-fluorouracil and concurrent radiation for high-grade gliomas. Am J Clin Oncol 18: 1-7, 1995

97. Larsen JM, Martin DR, Byrne ME: Recent advances in delivery through the blood-brain barrier. Curr Top Med Chem 14:1148-1160, 2014

98. Lee HK, Finniss S, Cazacu S, Bucris E, Ziv-Av A, Xiang C, et al: Mesenchymal stem cells deliver synthetic microRNA mimics to glioma cells and glioma stem cells and inhibit their cell migration and self-renewal. Oncotarget 4:346361,2013

99. Lee Titsworth W, Murad GJ, Hoh BL, Rahman M: Fighting fire with fire: the revival of thermotherapy for gliomas. Anticancer Res 34:565-574, 2014

100. Leggas M, Adachi M, Scheffer GL, Sun D, Wielinga P, Du $\mathrm{G}$, et al: Mrp4 confers resistance to topotecan and protects the brain from chemotherapy. Mol Cell Biol 24:7612-7621, 2004

101. Lei C, Cui Y, Zheng L, Chow PK, Wang CH: Development of a gene/drug dual delivery system for brain tumor therapy: potent inhibition via RNA interference and synergistic effects. Biomaterials 34:7483-7494, 2013

102. Liebner S, Fischmann A, Rascher G, Duffner F, Grote EH, Kalbacher H, et al: Claudin-1 and claudin-5 expression and tight junction morphology are altered in blood vessels of human glioblastoma multiforme. Acta Neuropathol 100:323-331, 2000

103. Lipinski CA, Lombardo F, Dominy BW, Feeney PJ: Experimental and computational approaches to estimate solubility and permeability in drug discovery and development settings. Adv Drug Deliv Rev 46:3-26, 2001

104. Lopez-Ramirez MA, Fischer R, Torres-Badillo CC, Davies HA, Logan K, Pfizenmaier K, et al: Role of caspases in cytokine-induced barrier breakdown in human brain endothelial cells. J Immunol 189:3130-3139, 2012

105. Lv H, Zhang S, Wang B, Cui S, Yan J: Toxicity of cationic lipids and cationic polymers in gene delivery. J Control Release 114:100-109, 2006

106. Madane RG, Mahajan HS: Curcumin-loaded nanostructured lipid carriers (NLCs) for nasal administration: design, characterization, and in vivo study. Drug Deliv [epub ahead of print], 2014

107. Madden SL, Cook BP, Nacht M, Weber WD, Callahan MR, Jiang Y, et al: Vascular gene expression in nonneoplastic and malignant brain. Am J Pathol 165:601-608, 2004

108. Mamot C, Nguyen JB, Pourdehnad M, Hadaczek P, Saito R, Bringas JR, et al: Extensive distribution of liposomes in rodent brains and brain tumors following convectionenhanced delivery. J Neurooncol 68:1-9, 2004

109. Matsukado K, Inamura T, Nakano S, Fukui M, Bartus RT, Black KL: Enhanced tumor uptake of carboplatin and survival in glioma-bearing rats by intracarotid infusion of bradykinin analog, RMP-7. Neurosurgery 39:125-134, 1996

110. McDannold N, Arvanitis CD, Vykhodtseva N, Livingstone MS: Temporary disruption of the blood-brain barrier by use of ultrasound and microbubbles: safety and efficacy evaluation in rhesus macaques. Cancer Res 72:3652-3663, 2012

111. Metz MZ, Gutova M, Lacey SF, Abramyants Y, Vo T, Gilchrist M, et al: Neural stem cell-mediated delivery of irinotecan-activating carboxylesterases to glioma: implications for clinical use. Stem Cells Transl Med 2:983-992, 2013

112. Montana V, Sontheimer H: Bradykinin promotes the chemotactic invasion of primary brain tumors. J Neurosci 31:4858-4867, 2011

113. Muldoon LL, Nilaver G, Kroll RA, Pagel MA, Breakefield $\mathrm{XO}$, Chiocca EA, et al: Comparison of intracerebral inoculation and osmotic blood-brain barrier disruption for deliv- 
ery of adenovirus, herpesvirus, and iron oxide particles to normal rat brain. Am J Pathol 147:1840-1851, 1995

114. Muldoon LL, Soussain C, Jahnke K, Johanson C, Siegal T, Smith QR, et al: Chemotherapy delivery issues in central nervous system malignancy: a reality check. J Clin Oncol 25:2295-2305, 2007

115. Munoz JL, Bliss SA, Greco SJ, Ramkissoon SH, Ligon KL, Rameshwar P: Delivery of functional anti-miR-9 by mesenchymal stem cell-derived exosomes to glioblastoma multiforme cells conferred chemosensitivity. Mol Ther Nucleic Acids 2: 126, 2013

116. Munoz JL, Rodriguez-Cruz V, Greco SJ, Nagula V, Scotto $\mathrm{KW}$, Rameshwar P: Temozolomide induces the production of epidermal growth factor to regulate MDR1 expression in glioblastoma cells. Mol Cancer Ther 13:2399-2411, 2014

117. Namba H, Kobayashi S, Iwadate Y, Saegusa T, Sato A, Watanabe Y, et al: Assessment of the brain areas perfused by superselective intra-arterial chemotherapy using single photon emission computed tomography with technetium99m-hexamethyl-propyleneamine oxime-technical note. Neurol Med Chir (Tokyo) 34:832-835, 1994

118. Navalitloha Y, Schwartz ES, Groothuis EN, Allen CV, Levy RM, Groothuis DR: Therapeutic implications of tumor interstitial fluid pressure in subcutaneous RG-2 tumors. Neuro Oncol 8:227-233, 2006

119. Neuwelt EA, Frenkel EP, Diehl JT, Maravilla KR, Vu LH, Clark WK, et al: Osmotic blood-brain barrier disruption: a new means of increasing chemotherapeutic agent delivery. Trans Am Neurol Assoc 104:256-260, 1979

120. Neuwelt EA, Hill SA, Frenkel EP, Diehl JT, Maravilla KR, Vu LH, et al: Osmotic blood-brain barrier disruption: pharmacodynamic studies in dogs and a clinical phase I trial in patients with malignant brain tumors. Cancer Treat Rep 65 (Suppl 2):39-43, 1981

121. Noell S, Ritz R, Wolburg-Buchholz K, Wolburg H, FallierBecker P: An allograft glioma model reveals the dependence of aquaporin-4 expression on the brain microenvironment. PLoS ONE 7:e36555, 2012

122. Ogunshola OO, Al-Ahmad A: HIF-1 at the blood-brain barrier: a mediator of permeability? High Alt Med Biol 13:153-161, 2012

123. Omuro AM, DeAngelis LM, Yahalom J, Abrey LE: Chemoradiotherapy for primary CNS lymphoma: an intentto-treat analysis with complete follow-up. Neurology 64:69-74, 2005

124. Ostermann S, Csajka C, Buclin T, Leyvraz S, Lejeune F, Decosterd LA, et al: Plasma and cerebrospinal fluid population pharmacokinetics of temozolomide in malignant glioma patients. Clin Cancer Res 10:3728-3736, 2004

125. Ostrom QT, Gittleman H, Liao P, Rouse C, Chen Y, Dowling J, et al: CBTRUS statistical report: primary brain and central nervous system tumors diagnosed in the United States in 2007-2011. Neuro Oncol 16 (Suppl 4):iv1-iv63, 2014

126. Ozduman K, Wollmann G, Piepmeier JM, van den Pol AN: Systemic vesicular stomatitis virus selectively destroys multifocal glioma and metastatic carcinoma in brain. $\mathbf{J}$ Neurosci 28:1882-1893, 2008

127. Papisov MI, Belov VV, Gannon KS: Physiology of the intrathecal bolus: the leptomeningeal route for macromolecule and particle delivery to CNS. Mol Pharm 10:15221532, 2013

128. Pardridge WM: Drug transport across the blood-brain barrier. J Cereb Blood Flow Metab 32:1959-1972, 2012

129. Postmes TJ, Hukkelhoven M, van den Bogaard AE, Halders SG, Coenegracht J: Passage through the blood-brain barrier of thyrotropin-releasing hormone encapsulated in liposomes. J Pharm Pharmacol 32:722-724, 1980

130. Rainov NG: A phase III clinical evaluation of herpes sim- plex virus type 1 thymidine kinase and ganciclovir gene therapy as an adjuvant to surgical resection and radiation in adults with previously untreated glioblastoma multiforme. Hum Gene Ther 11:2389-2401, 2000

131. Reagan MR, Kaplan DL: Concise review: mesenchymal stem cell tumor-homing: detection methods in disease model systems. Stem Cells 29:920-927, 2011

132. Reiber H, Felgenhauer K: Protein transfer at the blood cerebrospinal fluid barrier and the quantitation of the humoral immune response within the central nervous system. Clin Chim Acta 163:319-328, 1987

133. Reitz M, Demestre M, Sedlacik J, Meissner H, Fiehler J, Kim SU, et al: Intranasal delivery of neural stem/progenitor cells: a noninvasive passage to target intracerebral glioma. Stem Cells Transl Med 1:866-873, 2012

134. Ren H, Boulikas T, Lundstrom K, Söling A, Warnke PC, Rainov NG: Immunogene therapy of recurrent glioblastoma multiforme with a liposomally encapsulated replicationincompetent Semliki forest virus vector carrying the human interleukin-12 gene-a phase I/II clinical protocol. J Neurooncol 64:147-154, 2003

135. Rodriguez-Cruz V, Munoz JL, Rameshwar P: CB-07. Mechanisms of chemoresistance in CD133-expressing glioblastoma cells: the role of drug efflux transporters. Neuro Oncol 14 (Suppl 6):vi87, 2012 (Abstract)

136. Saito R, Bringas JR, McKnight TR, Wendland MF, Mamot C, Drummond DC, et al: Distribution of liposomes into brain and rat brain tumor models by convection-enhanced delivery monitored with magnetic resonance imaging. Cancer Res 64:2572-2579, 2004

137. Saito R, Krauze MT, Bringas JR, Noble C, McKnight TR, Jackson P, et al: Gadolinium-loaded liposomes allow for real-time magnetic resonance imaging of convectionenhanced delivery in the primate brain. Exp Neurol 196:381-389, 2005

138. Sampson JH, Akabani G, Friedman AH, Bigner D, Kunwar S, Berger MS, et al: Comparison of intratumoral bolus injection and convection-enhanced delivery of radiolabeled antitenascin monoclonal antibodies. Neurosurg Focus 20(2):E14, 2006

139. Sarin H, Kanevsky AS, Wu H, Sousa AA, Wilson CM, Aronova MA, et al: Physiologic upper limit of pore size in the blood-tumor barrier of malignant solid tumors. J Transl Med 7:51, 2009

140. Sathornsumetee S, Rich JN: New treatment strategies for malignant gliomas. Expert Rev Anticancer Ther 6:10871104,2006

141. Sawyer AJ, Saucier-Sawyer JK, Booth CJ, Liu J, Patel T, Piepmeier JM, et al: Convection-enhanced delivery of camptothecin-loaded polymer nanoparticles for treatment of intracranial tumors. Drug Deliv Transl Res 1:34-42, 2011

142. Schebesch KM, Proescholdt M, Höhne J, Hohenberger C, Hansen E, Riemenschneider MJ, et al: Sodium fluoresceinguided resection under the YELLOW $560 \mathrm{~nm}$ surgical microscope filter in malignant brain tumor surgery - a feasibility study. Acta Neurochir (Wien) 155:693-699, 2013

143. Schlageter KE, Molnar P, Lapin GD, Groothuis DR: Microvessel organization and structure in experimental brain tumors: microvessel populations with distinctive structural and functional properties. Microvasc Res 58:312-328, 1999

144. Seifert S, Sontheimer H: Bradykinin enhances invasion of malignant glioma into the brain parenchyma by inducing cells to undergo amoeboid migration. J Physiol 592:5109_ 5127,2014

145. Shin BJ, Burkhardt JK, Riina HA, Boockvar JA: Superselective intra-arterial cerebral infusion of novel agents after blood-brain disruption for the treatment of recurrent glioblastoma multiforme: a technical case series. Neurosurg Clin N Am 23:323-329, ix-x, 2012 
146. Sonabend AM, Carminucci AS, Amendolara B, Bansal M, Leung R, Lei L, et al: Convection-enhanced delivery of etoposide is effective against murine proneural glioblastoma. Neuro Oncol 16:1210-1219, 2014

147. Squire LR, Bloom FE, Spitzer NC, du Lac S, Ghosh A, Berg D: Fundamental Neuroscience, ed 3. Boston: Elsevier, 2008

148. Strazielle N, Ghersi-Egea JF: Physiology of blood-brain interfaces in relation to brain disposition of small compounds and macromolecules. Mol Pharm 10:1473-1491, 2013

149. Stupp R, Mason WP, van den Bent MJ, Weller M, Fisher B, Taphoorn MJ, et al: Radiotherapy plus concomitant and adjuvant temozolomide for glioblastoma. N Engl J Med 352:987-996, 2005

150. Tate MC, Aghi MK: Biology of angiogenesis and invasion in glioma. Neurotherapeutics 6:447-457, 2009

151. Teng J, Hejazi S, Badr CE, Tannous BA: Systemic anticancer neural stem cells in combination with a cardiac glycoside for glioblastoma therapy. Stem Cells 32:2021-2032, 2014

152. Theodotou C, Shah AH, Hayes S, Bregy A, Johnson JN, Aziz-Sultan MA, et al: The role of intra-arterial chemotherapy as an adjuvant treatment for glioblastoma. Br J Neurosurg 28:438-446, 2014

153. Thévenot E, Jordão JF, O'Reilly MA, Markham K, Weng YQ, Foust KD, et al: Targeted delivery of self-complementary adeno-associated virus serotype 9 to the brain, using magnetic resonance imaging-guided focused ultrasound. Hum Gene Ther 23:1144-1155, 2012

154. Thomas AA, Brennan CW, DeAngelis LM, Omuro AM: Emerging therapies for glioblastoma. JAMA Neurol 71:1437-1444, 2014

155. Treat LH, McDannold N, Vykhodtseva N, Zhang Y, Tam $\mathrm{K}$, Hynynen K: Targeted delivery of doxorubicin to the rat brain at therapeutic levels using MRI-guided focused ultrasound. Int J Cancer 121:901-907, 2007

156. Tros de Ilarduya C, Sun Y, Düzgüneş N: Gene delivery by lipoplexes and polyplexes. Eur J Pharm Sci 40:159-170, 2010

157. Tsujiuchi T, Natsume A, Motomura K, Kondo G, Ranjit M, Hachisu R, et al: Preclinical evaluation of an $\mathrm{O}(6)$ methylguanine-DNA methyltransferase-siRNA/liposome complex administered by convection-enhanced delivery to rat and porcine brains. Am J Transl Res 6:169-178, 2014

158. van Deurs B, Koehler JK: Tight junctions in the choroid plexus epithelium. A freeze-fracture study including complementary replicas. J Cell Biol 80:662-673, 1979

159. Vecil GG, Lang FF: Clinical trials of adenoviruses in brain tumors: a review of Ad-p53 and oncolytic adenoviruses. J Neurooncol 65:237-246, 2003

160. Vogelbaum MA: Convection enhanced delivery for the treatment of malignant gliomas: symposium review. J Neurooncol 73:57-69, 2005

161. Vogelbaum MA, Sampson JH, Kunwar S, Chang SM, Shaffrey M, Asher AL, et al: Convection-enhanced delivery of cintredekin besudotox (interleukin-13-PE38QQR) followed by radiation therapy with and without temozolomide in newly diagnosed malignant gliomas: phase 1 study of final safety results. Neurosurgery 61:1031-1038, 2007

162. Voges J, Reszka R, Gossmann A, Dittmar C, Richter R, Garlip G, et al: Imaging-guided convection-enhanced delivery and gene therapy of glioblastoma. Ann Neurol 54:479487, 2003

163. Wang R, Chadalavada K, Wilshire J, Kowalik U, Hovinga KE, Geber A, et al: Glioblastoma stem-like cells give rise to tumour endothelium. Nature 468:829-833, 2010

164. Warren K, Jakacki R, Widemann B, Aikin A, Libucha M, Packer R, et al: Phase II trial of intravenous lobradimil and carboplatin in childhood brain tumors: a report from the Children's Oncology Group. Cancer Chemother Pharmacol 58:343-347, 2006

165. Warren KE, Patel MC, Aikin AA, Widemann B, Libucha M, Adamson PC, et al: Phase I trial of lobradimil (RMP7) and carboplatin in children with brain tumors. Cancer Chemother Pharmacol 48:275-282, 2001

166. Warth A, Mittelbronn M, Wolburg H: Redistribution of the water channel protein aquaporin- 4 and the $\mathrm{K}+$ channel protein Kir4.1 differs in low- and high-grade human brain tumors. Acta Neuropathol 109:418-426, 2005

167. Watanabe M, Tanaka R, Hondo H, Kuroki M: Effects of antineoplastic agents and hyperthermia on cytotoxicity toward chronically hypoxic glioma cells. Int J Hyperthermia 8:131-138, 1992

168. Wei KC, Chu PC, Wang HY, Huang CY, Chen PY, Tsai $\mathrm{HC}$, et al: Focused ultrasound-induced blood-brain barrier opening to enhance temozolomide delivery for glioblastoma treatment: a preclinical study. PLoS ONE 8:e58995, 2013

169. Wen PY, Kesari S: Malignant gliomas in adults. N Engl J Med 359:492-507, 2008

170. White E, Bienemann A, Taylor H, Hopkins K, Cameron A, Gill S: A phase I trial of carboplatin administered by convection-enhanced delivery to patients with recurrent/ progressive glioblastoma multiforme. Contemp Clin Trials 33:320-331, 2012

171. Whitin JC, Jang T, Merchant M, Yu TT, Lau K, Recht B, et al: Alterations in cerebrospinal fluid proteins in a presymptomatic primary glioma model. PLoS ONE 7:e49724, 2012

172. Winn HR: Youmans Neurological Surgery, ed 6. Philadelphia: Saunders, 2011

173. Witham TF, Fukui MB, Meltzer CC, Burns R, Kondziolka D, Bozik ME: Survival of patients with high grade glioma treated with intrathecal thiotriethylenephosphoramide for ependymal or leptomeningeal gliomatosis. Cancer 86:1347-1353, 1999

174. Wong AD, Ye M, Levy AF, Rothstein JD, Bergles DE, Searson PC: The blood-brain barrier: an engineering perspective. Front Neuroeng 6:7, 2013

175. Xiong W, Candolfi M, Liu C, Muhammad AK, Yagiz K, Puntel M, et al: Human Flt3L generates dendritic cells from canine peripheral blood precursors: implications for a dog glioma clinical trial. PLoS ONE 5:e11074, 2010

176. Yamashita Y, Krauze MT, Kawaguchi T, Noble CO, Drummond DC, Park JW, et al: Convection-enhanced delivery of a topoisomerase I inhibitor (nanoliposomal topotecan) and a topoisomerase II inhibitor (pegylated liposomal doxorubicin) in intracranial brain tumor xenografts. Neuro Oncol 9:20-28, 2007

177. Yang FY, Horng SC: Chemotherapy of glioblastoma by targeted liposomal platinum compounds with focused ultrasound. Conf Proc IEEE Eng Med Biol Soc 2013:62896292, 2013

178. Yang FY, Wang HE, Liu RS, Teng MC, Li JJ, Lu M, et al: Pharmacokinetic analysis of 111 in-labeled liposomal Doxorubicin in murine glioblastoma after blood-brain barrier disruption by focused ultrasound. PLoS ONE 7:e45468, 2012

179. Yang W, Barth RF, Huo T, Nakkula RJ, Weldon M, Gupta $\mathrm{N}$, et al: Radiation therapy combined with intracerebral administration of carboplatin for the treatment of brain tumors. Radiat Oncol 9:25, 2014

180. Yang Z, Xiang B, Dong D, Wang Z, Li J, Qi X: Dual receptor-specific peptides modified liposomes as VEGF siRNA vector for tumor-targeting therapy. Curr Gene Ther 14:289-299, 2014

181. Yang ZZ, Li JQ, Wang ZZ, Dong DW, Qi XR: Tumortargeting dual peptides-modified cationic liposomes for delivery of siRNA and docetaxel to gliomas. Biomaterials 35:5226-5239, 2014 
182. Yao L, Song Q, Bai W, Zhang J, Miao D, Jiang M, et al: Facilitated brain delivery of poly (ethylene glycol)-poly (lactic acid) nanoparticles by microbubble-enhanced unfocused ultrasound. Biomaterials 35:3384-3395, 2014

183. Yilmaz G, Vital S, Yilmaz CE, Stokes KY, Alexander JS, Granger DN: Selectin-mediated recruitment of bone marrow stromal cells in the postischemic cerebral microvasculature. Stroke 42:806-811, 2011

184. Youn P, Chen Y, Furgeson DY: A myristoylated cellpenetrating peptide bearing a transferrin receptor-targeting sequence for neuro-targeted siRNA delivery. Mol Pharm 11:486-495, 2014

185. Zagouri F, Sergentanis TN, Bartsch R, Berghoff AS, Chrysikos D, de Azambuja E, et al: Intrathecal administration of trastuzumab for the treatment of meningeal carcinomatosis in HER2-positive metastatic breast cancer: a systematic review and pooled analysis. Breast Cancer Res Treat 139:13-22, 2013
186. Zhou J, Atsina KB, Himes BT, Strohbehn GW, Saltzman WM: Novel delivery strategies for glioblastoma. Cancer J 18:89-99, 2012

\section{Author Contributions}

Conception and design: all authors. Acquisition of data: all authors. Analysis and interpretation of data: all authors. Drafting the article: all authors. Critically revising the article: all authors. Reviewed submitted version of manuscript: all authors.

\section{Correspondence}

Aaron A. Cohen-Gadol, Goodman Campbell Brain and Spine, Indiana University, Department of Neurological Surgery, $355 \mathrm{~W}$ 16th St., Ste. 5100, Indianapolis, IN 462022. email: acohenmd@ gmail.com. 